\title{
Radiation effects in natural quartz crystals
}

\author{
Harish Bahadur · Hélène Tissoux · Teruo Usami • \\ Shin Toyoda
}

Received: 15 May 2007/Accepted: 20 August 2007/Published online: 25 September 2007

(C) Springer Science+Business Media, LLC 2007

\begin{abstract}
Optically clear, as visually observed, natural quartz crystals of Brazilian and Arkansas origins, which exhibit $\mathrm{Al}-\mathrm{OH}^{-}$-centers in their as-received conditions, have been measured for their low temperature ESR spectra to see the presence of Al-hole centers. The ESR spectra revealed the presence of Al-hole centers in their asreceived conditions. These centers showed an increase in their strength upon irradiation with a ${ }^{60} \mathrm{C} 0$ source. Such observations were exhibited by $\mathrm{Al}-\mathrm{OH}^{-}$-centers as noticed earlier. The crystals were thus noticed to exhibit the presence of $\mathrm{Al}-\mathrm{OH}^{-}$-centers and also Al-hole centers in their as-received conditions. The observations match with the results on cultured quartz where irradiation breaks away the Al-alkali centers into a mixture of $\mathrm{Al}-\mathrm{OH}^{-}$- and $\mathrm{Al}$ hole centers. It is thus concluded that the natural crystals, which exhibit the presence of these centers in their asreceived condition, have been irradiated in nature with a low dose.
\end{abstract}

\section{Introduction}

Alpha quartz continues to be of scientific interest. The major stimulus in research in quartz crystals is due to the varied technological applications for which quartz is uniquely suited, such as in optics, clocks for

H. Bahadur $(\bowtie)$

National Physical Laboratory, New Delhi 110012, India

e-mail: hbahadur@mail.nplindia.ernet.in

H. Tissoux $\cdot$ T. Usami $\cdot$ S. Toyoda

Department of Applied Physics, Okayama University of Science,

Okayama 700-0005, Japan microprocessors, temperature and mass sensors, accelerometers, and a variety of electronic devices including crystal oscillators and filters for precision frequency control, communications and generally in signal processing in computers. Recent development of Quartz Crystal Microbalance (QCM) has added a new dimension to the application of quartz crystals wherein almost every conceivable aspect in the analytical measurements can be performed by using a quartz crystal resonator. In the present day technology, the name 'Quartz' has become a symbol of quality for a variety of precision equipment. Until about a half century before, the use of quartz crystal in industry was mainly supported by the ready availability of large amount of single optical grade natural quartz material. Continued efforts on hydrothermal synthesis of cultured quartz during last over four decades have come to a stage that much of the present industrial demand of quartz crystal is satisfied by the man made material except where a radiation-resistant quartz is required for aerospace applications. It would thus be technologically very important to process quartz crystals for their low radiationsensitivity.

The presence of impurities in quartz, such as aluminum, alkalis like $\mathrm{Na}$ or $\mathrm{Li}$ and also hydrogen, limits the $\mathrm{Q}$ (quality factor) and therefore affect nearly every application of it as a device. Because of its various technological applications, quartz is also grown in the laboratory under controlled conditions for specific applications. Additionally, some post growth treatment may also be given to quartz stone which may change its composition for some special applications. The cultured quartz is grown hydrothermally and therefore hydrogen is an ubiquitous impurity in quartz. Further, natural quartz is almost always used as the starting material for the hydrothermal synthesis of cultured quartz. Thus, the natural quartz continues to be a 
subject matter of serious scientific study. Point defects in natural and cultured quartz have been have been under investigation for over five decades. Still, there remains a lot to investigate for corroborating the various complex issues relating to these defects and their role in the device performance. Much of our present day understanding has come from the study of radiation effects and monitoring the spectroscopic signals coming from the radiation-induced changes in the configuration of point defects of the postirradiated quartz. An analysis of the signal from the postirradiated defects helps in deriving the structure of their precursors. It is known [1-7] that each quartz has trivalent aluminum $\left(\right.$ as $\mathrm{Al}^{3+}$ ) at substitutional sites of $\mathrm{Si}^{4+}$. The electron excess defect of $\mathrm{Al}^{3+}$ center is compensated by the presence of interstitial monovalent impurity either alkalis $\left(\mathrm{M}^{+}\right)$such as $\mathrm{Na}^{+}, \mathrm{Li}^{+}$, or protons near aluminum in the open c-axis channels parallel to the growth direction of the crystals. When exposed to ionizing radiation, the $\mathrm{Al}-\mathrm{M}^{+}$ centers break away into a mixture of $\mathrm{Al}$-hole and $\mathrm{Al}-\mathrm{OH}^{-}$centers [1-7].

We present here results of our further investigations on natural quartz crystals of Arkansas and Brazilian origins. These crystals are those on which near infrared investigations coupled with sweeping and irradiation have been reported earlier in many publications [8-13]. These crystals have nearly same concentration of aluminum impurity but have widely different H-levels. The Arkansas quartz has low-H while Brazilian quartz has high-H levels. In the asreceived conditions, both the crystals showed the presence of $\mathrm{Al}-\mathrm{OH}^{-}$-centers [8-13].

We expect that the natural irradiation could be one of the causes to produce the $\mathrm{Al}-\mathrm{OH}$ centers in natural crystalline quartz. Additionally, if the $\mathrm{Al}-\mathrm{OH}^{-}$-centers are formed due to irradiation, it should be accompanied by the Al-hole centers as well. This expectation has been verified.

\section{Experimental procedure}

Natural quartz crystals were investigated in their asreceived condition and after irradiation with an accumulated dose of $1.21 \mathrm{kGy}$. The dose rate was $3.0 \mathrm{C} / \mathrm{kgh}$ $(101 \mathrm{~Gy} / \mathrm{h})$ of ${ }^{60} \mathrm{C} 0$ source at Takasaki Research Institute of Japan Atomic Energy Research Institute. The electron spin resonance method was used to detect the presence of Al-hole centers in these samples of quartz crystals. Measurements were done at liquid nitrogen temperatures to monitor the impurity-related defects. The ESR spectrometer, JEOL PX 2300 of Okayama University of Science, Okayama, Japan was used. The crystals were crushed, powdered, and sieved through a mesh of less than $217 \mu \mathrm{m}$ and greater than $140 \mu \mathrm{m}$. The particles in this size range were collected. A quantity of $100 \mathrm{mg}$ of both the samples of Brazilian and Arkansas quartz was collected in a glass tube which was transferred to the microwave cavity of the spectrometer for the measurements.

\section{Results and discussion}

As mentioned before, the crystals studied in the present work have been studied earlier [8-13] for their radiation effects using near infrared absorption spectroscopy. For a ready reference, Fig. 1 shows the near IR spectra for both the crystals in their as-received condition. In the figure, the bands at 3,367 and 3,306 wave numbers are known to be due to the presence of $\mathrm{Al}-\mathrm{OH}^{-}$-centers with proton located at long- and short-Al-O bonds, respectively. Many of the other bands still remain unidentified. Irradiation effects on these crystals were studied [10-13] by irradiating them at $77 \mathrm{~K}$ before and after $300 \mathrm{~K}$. It was noticed that the $77 \mathrm{~K}$-irradiation did not increase the strength of $\mathrm{Al}-\mathrm{OH}^{-}$centers but in most cases transferred the protons from the long bond $\mathrm{Al}-\mathrm{OH}^{-}$to the short-bond to $\mathrm{Al}-\mathrm{OH}^{-}$so that both the bands become equally populated with protons. There was however, no net increase of $\mathrm{Al}-\mathrm{OH}^{-}$-centers at $77 \mathrm{~K}$ irradiation. This was so because at this temperature, the alkalis from the aluminum centers would not be able to move away so that protons may replace them. Upon irradiation at $300 \mathrm{~K}$, these crystals showed an increase in the $\mathrm{Al}-\mathrm{OH}^{-}$-centers. This was due to breakaway of Al-alkali centers into a mixture of $\mathrm{Al}-$ hole and $\mathrm{Al}-\mathrm{OH}^{-}$-centers. On the other hand, in the case of cultured quartz (such as in Fig. 2), there is no evidence of $\mathrm{Al}-\mathrm{OH}^{-}$-centers in the asgrown condition. It is known [4] that the $\mathrm{Al}-\mathrm{OH}^{-}$-centers in cultured quartz can be produced either by sweeping in $\mathrm{H}$-ambient or by irradiation beyond $200 \mathrm{~K}$. In the case of

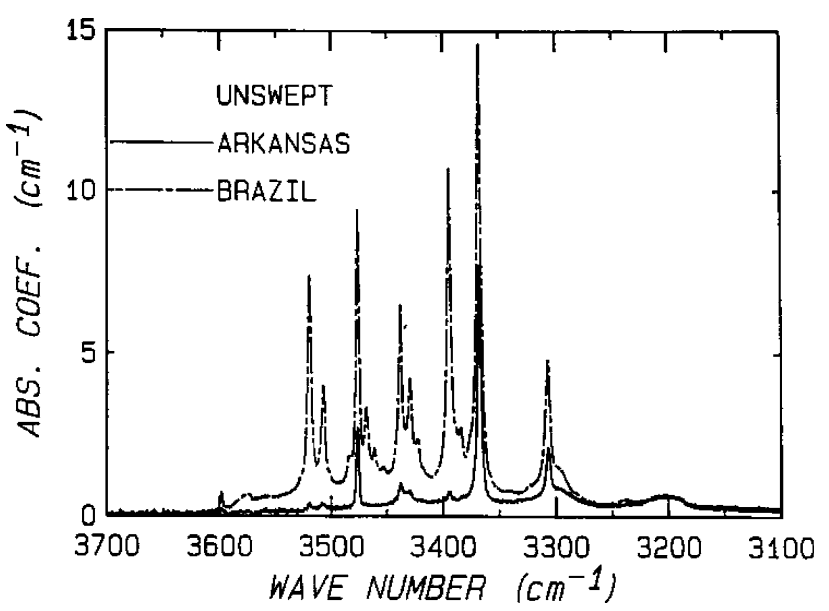

Fig. 1 Near IR spectra of natural quartz crystals of Brazilian and Arkansas origin in their as-received conditions (after Bahadur [9]). It may be noticed that the bands at 3,367 and 3,306 wave numbers occur in their as-received (or as-grown) conditions 


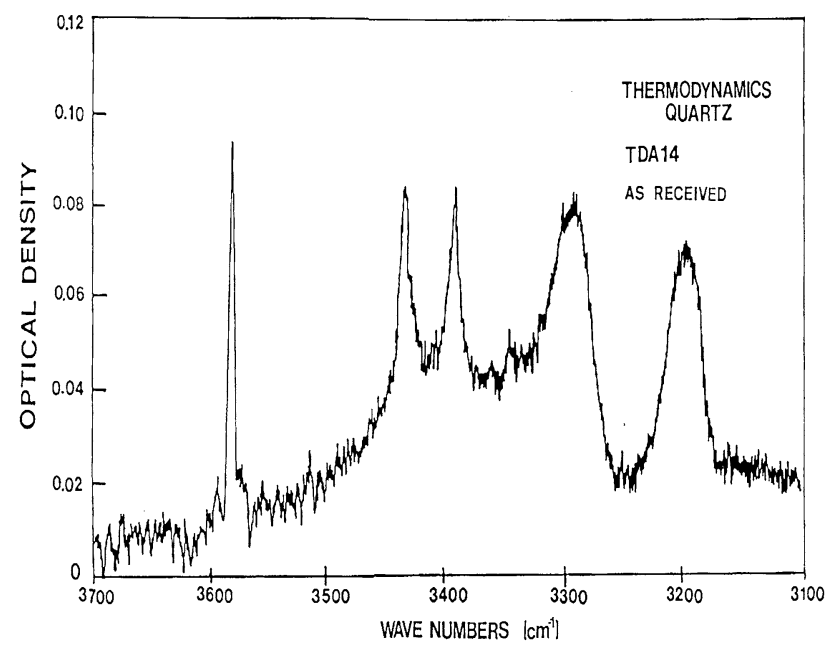

Fig. 2 Near IR spectra of cultured quartz crystal in its as-grown condition. It may be noticed that there is no appearance of the bands at 3,367 and 3,306 wave numbers in its as-received or as-grown condition (after Bahadur [8])

sweeping of cultured quartz, the protons from the $\mathrm{H}$ ambient will get trapped at Al-sites to replace alkalis which have moved from Al centers during sweeping under the effect of electric field and the high temperature. If the sweeping is complete, all the Al-alkali centers will get converted to $\mathrm{Al}-\mathrm{OH}^{-}$because all the aluminum ions will be charge compensated with protons. In such a case, there will not be any permanent effect of $300 \mathrm{~K}$-irradiation [5]. In the case of natural quartz also, H-sweeping increases the strength of $\mathrm{Al}-\mathrm{OH}^{-}$-centers to the maximum to compensate all aluminum with protons if the sweeping is complete [9, 10]. In both the cases of natural as well as cultured quartz, the Al-hole centers will not be produced by sweeping under $\mathrm{H}$-ambient. The Al-hole centers get produced only when the quartz is irradiated at temperatures beyond $200 \mathrm{~K}$. This center is usually observed by ESR techniques. The line shape of the ESR signal depends upon the crystal symmetry and orientation with respect to the magnetic field $[14,15]$. A representative ESR spectrum of quartz for the Al-hole centers for a crystalline quartz parallel to the magnetic field [6] is shown in Fig. 3. For a powdered quartz samples [16, 17], Fig. 4 depicts a representative ESR spectrum. In the ESR spectra of Al-hole centers in quartz crystals, a number of hyperfine lines are observed $[14,15,18-20]$ due to the nuclear spins and quadruple splitting $\mathrm{Q}\left[I_{\mathrm{z}}^{2}-(\mathrm{I} / 3)(\mathrm{I}+1)\right]$ of ${ }^{27} \mathrm{Al}$. Figures 5 and 6 depict the ESR spectra in quartz samples corresponding to the Alhole centers of Brazilian and Arkansas origin respectively observed at $80 \mathrm{~K}$ in their as-received conditions. The near IR spectra for these crystals in their as-received conditions are shown in Fig. 1. These spectra also show the presence of $\mathrm{Al}-\mathrm{OH}^{-}$-centers in them in their as-received conditions. Figures 7 and 8 show the expanded view of the ESR

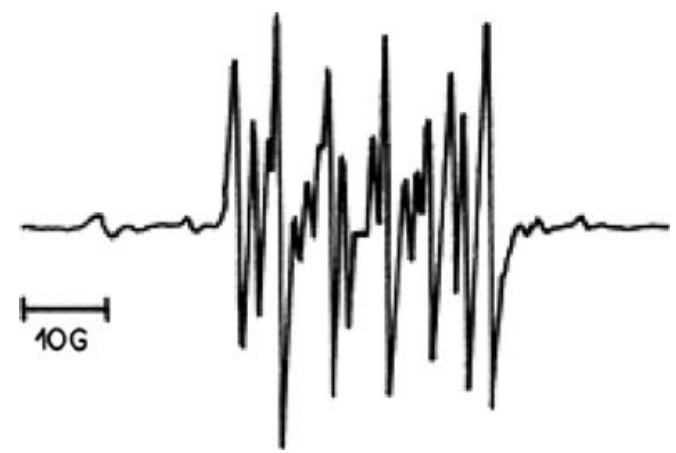

Fig. 3 ESR signal of Al-hole centers for a quartz crystal with magnetic field parallel to c-axis (after Halliburton et al. [6])

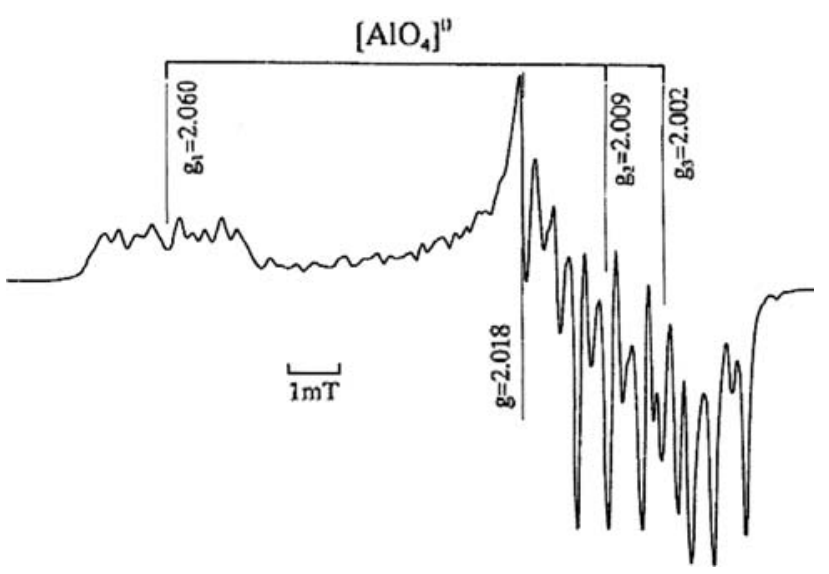

Fig. 4 The low temperature ( $\sim 77 \mathrm{~K})$ ESR spectrum of powdered natural quartz samples representing the Al-hole centers (after Toyoda [16])

spectra for the Al-hole centers taken from Figs. 5 and 6, respectively. The occurrence of Al-hole centers, as observed in the ESR spectra and $\mathrm{Al}-\mathrm{OH}^{-}$-centers as observed in their near infrared spectra, in their as-received condition suggests that the crystals have received the radiation dose. The source of radiation could perhaps be some radioactive element in the vicinity of the location where these crystals were grown in nature.

We have investigated the effect of irradiation on the Al-hole centers on these crystals. As mentioned earlier, the irradiation facility of ${ }^{60} \mathrm{C} 0$ source at Takasaki Research Institute of Japan Atomic Energy Research Institute was used. The dose rate was $3.0 \mathrm{C} / \mathrm{kgh}(101 \mathrm{~Gy} / \mathrm{h})$. The crystals were irradiated for the maximum dose of $1.21 \mathrm{kGy}$. Figures 9 and 10 and depict the results for the Brazilian and Arkansas samples after irradiation with a dose of $1.21 \mathrm{kGy}$. As expected, it was noticed that the strength of the Al-hole centers increased after irradiation. It has been described earlier [1-8] that the $\mathrm{Al}-\mathrm{OH}^{-}$-centers also show an increase after irradiation. 


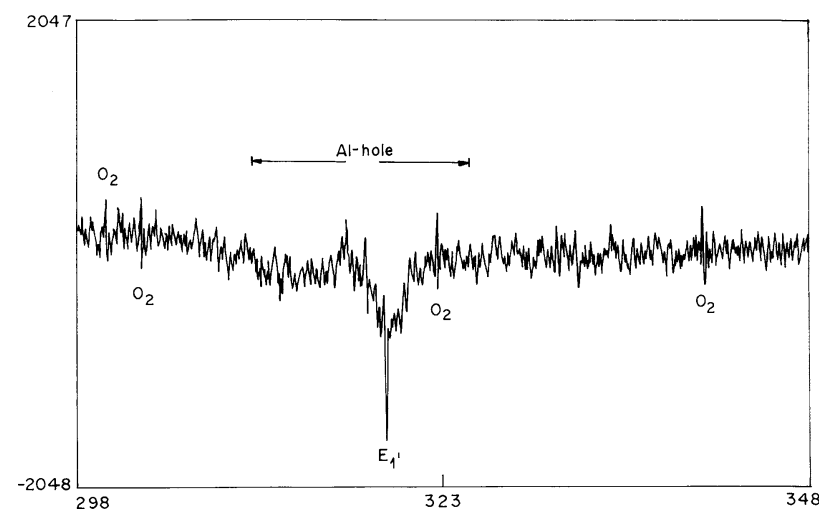

Fig. 5 The ESR spectrum of the Brazilian quartz crystals in its as-received condition observed at $80 \mathrm{~K}$. The spectrum represents the quadruple splitting of ${ }^{27} \mathrm{Al}$ nuclei. In addition, a strong signal corresponding to the spectrum of $\mathrm{E}_{1}^{\prime}$ is seen in this case also

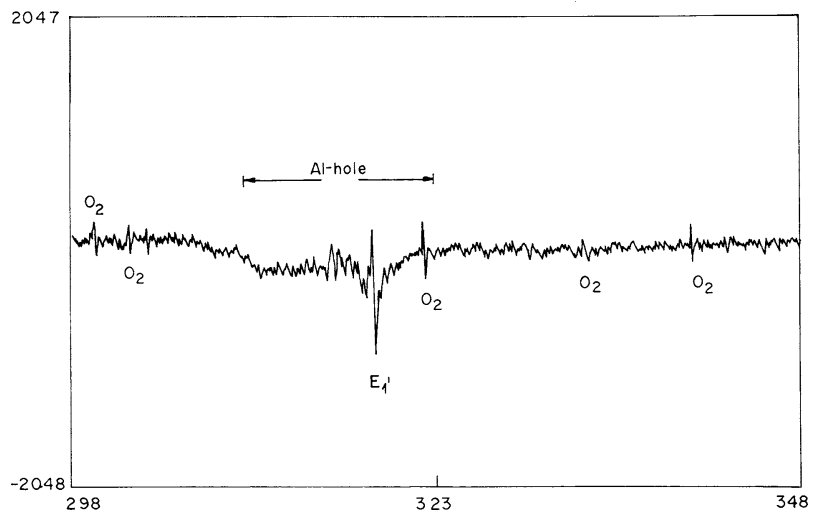

Fig. 6 The ESR spectrum of the Arkansas quartz crystals in its asreceived condition observed at $80 \mathrm{~K}$. The spectrum represents the quadruple splitting of ${ }^{27} \mathrm{Al}$ nuclei. In addition, a strong signal corresponding to the spectrum of $\mathrm{E}_{1}^{\prime}$ is also seen

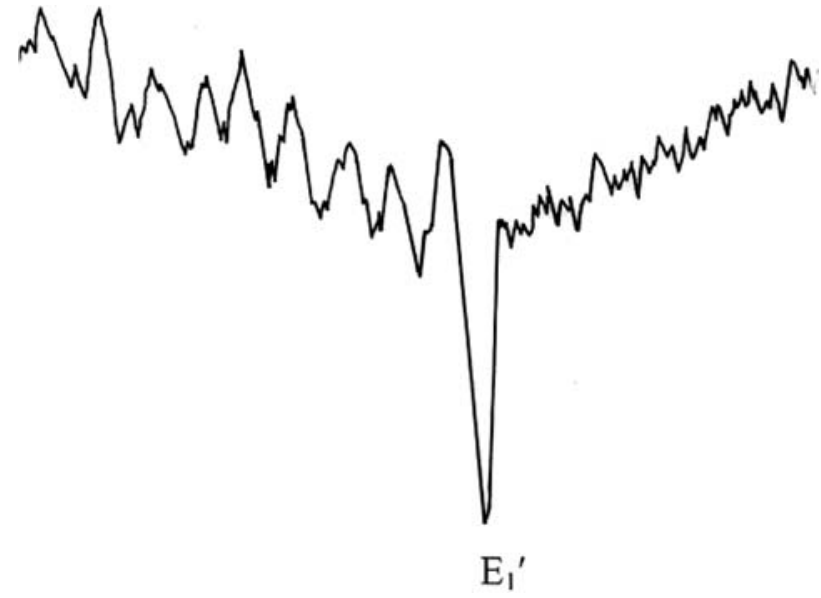

Fig. 7 Expanded view of the ESR spectrum of Al-hole centers in the as-received Brazilian quartz samples for which the complete spectrum is shown in Fig. 5

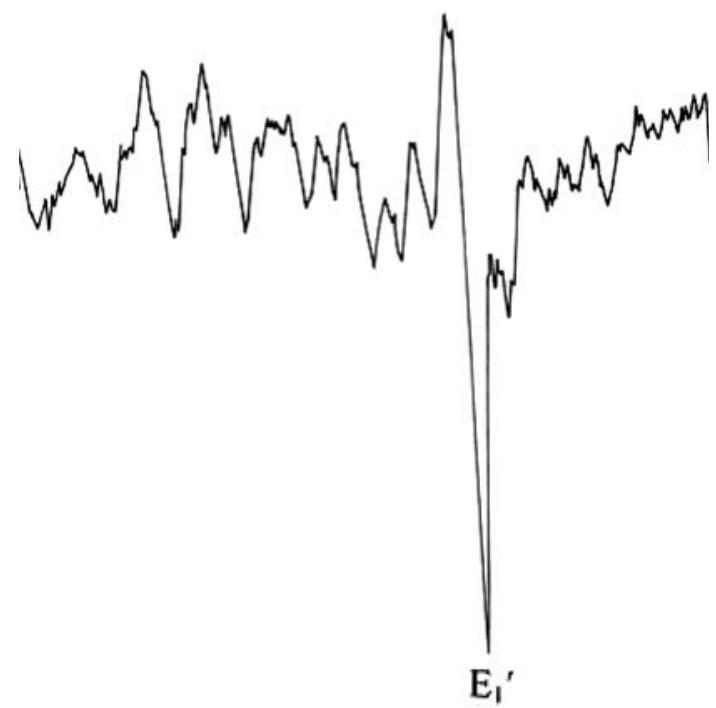

Fig. 8 Expanded view of the ESR spectrum of Al-hole centers in the as-received Arkansas quartz samples for which the complete spectrum is shown in Fig. 6

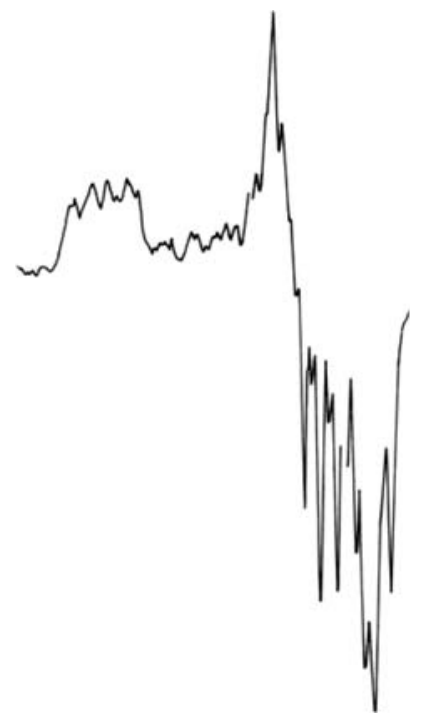

Fig. 9 ESR spectrum for the Al-hole centers in the Brazilian natural quartz after irradiating at $300 \mathrm{~K}$ with a dose of $1.21 \mathrm{kGy}$. The spectrometer parameters were; Microwave Frequency $=8934.143 \mathrm{MHz}$, Mod. Freq. $=100 \mathrm{kHz}$ modulation width $=0.1 \mathrm{mT}$, time const. $=0.03$, microwave power $=5 \mathrm{~mW}$, sweep time $=30 \mathrm{~s}$. $\mathrm{CH} 1$ amplitude $=1,000$

It is important to note here that here that the cultured crystals do not show the evidence of $\mathrm{Al}-\mathrm{OH}^{-}$-centers in their as-grown conditions (Fig. 2). Thus, in the as-grown cultured quartz, none of the aluminum centers are compensated with protons. However, when the cultured crystal are irradiated, the $\mathrm{Al}-\mathrm{OH}^{-}$- and $\mathrm{Al}$-hole centers are formed which can be monitored by near infrared absorption and ESR techniques respectively. In general, the formation of $\mathrm{Al}-\mathrm{OH}^{-}$- and Al-hole centers occur simultaneously when the Al-alkali centers break away under the influence of 


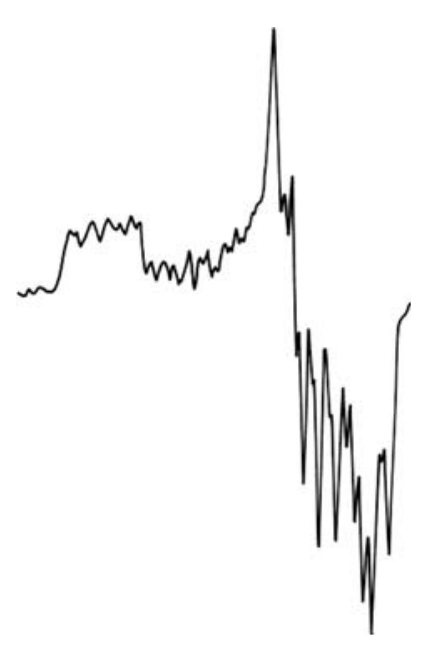

Fig. 10 ESR spectrum for the Al-hole centers in the Arkansas natural quartz after irradiating at $300 \mathrm{~K}$ with a dose of $1.21 \mathrm{kGy}$. The spectrometer parameters were identical as for the Fig. 9 except for the CH1 amplitude set at 700

irradiation. Both types of crystals, when swept in hydrogen atmosphere show only an increase of $\mathrm{Al}-\mathrm{OH}$ centers. In such a case, the protons from the ambient replace alkalis, mostly $\mathrm{Li}$ in cultured crystals and some $\mathrm{Na}$ also in the case of natural crystals. That the $\mathrm{Na}$ is present in natural quartz has been observed by the acoustic loss measurements of Martin $[1,2]$. The present results confirm that the formation of Al-hole in natural quartz also proceeds in the way as in the case of high purity cultured quartz, where irradiation breaks away the $\mathrm{Al}-\mathrm{M}^{+}$centers into a mixture of $\mathrm{Al}$-hole and $\mathrm{Al}-\mathrm{OH}^{-}$-centers [3-7]. Our measurement show that these crystals have received natural radiation during growth. Dose dependence of these centers will be reported later.

\section{Summary and conclusions}

We have investigated natural visually optically quartz crystals of Brazilian and Arkansas origins. These crystals were earlier studied for the near infrared absorption measurements and exhibited the presence of $\mathrm{Al}-\mathrm{OH}^{-}$-centers which increased upon irradiation. In the present work, we have investigated the presence of Al-hole in these crystals in their as-received condition and after irradiation. The centers were found to show an increase after irradiation. A discussion has been presented which supports the view that the natural crystals showing the presence of $\mathrm{Al}-\mathrm{OH}^{-}$-centers in their as-received condition have received a radiation dose during their growth. This was verified by the presence of Al-hole centers in their as-received condition. Thus, as has been established for the cultured quartz that Al-alkali centers break away under the influence of radiation into a mixture of $\mathrm{Al}$-hole and $\mathrm{Al}-\mathrm{OH}^{-}$, the mechanism is also applicable for natural quartz as well. The only difference between the natural and cultured quartz appears to be forthcoming is that while it is important to irradiate cultured quartz in laboratory for producing the Al-hole and $\mathrm{Al}-\mathrm{OH}^{-}$, such centers in natural quartz exist because they already have received the irradiation in nature.

Acknowledgments The authors are thankful to Dr. Vikram Kumar, Director, National Physical Laboratory, New Delhi for his encouragement in the work and Okayama University of Science for the support. This work was also supported by the Japan Society for promotion of Science (JSPS) by way of an award of invitation fellowship to Harish Bahadur. Hélène Tissoux was a JSPS post doc at Okayama University of Science. T. Usami is a research student supported by JSPS at OUS. The authors also thank Professor Joel Martin of Oklahoma State University and Dr. J.C. King of Sandia National Laboratories, Albuquerque, NM (now retired) for the gift of Arkansas and Brazilian crystals and their encouragement to investigate natural quartz.

\section{References}

1. J.J. Martin, J. Appl. Phys. 56, 2536 (1984)

2. J.J. Martin, in Proceedings of the 38 th Annual Frequency Control Symposium (1984), p. 16. Copies available from National Technical Information Service (NTIS), 5285 Port Royal Road, Sills Bldg., Springfield, VA 22161

3. L.E. Halliburton, J.J. Martin, W.A. Sibley, in Study of Defects Produced by Growth, Post Treatment and Fabrication of Quartz (Oklahoma State University, RADC-TR-81-276, Oct. 1981). Copies available from Rome Air Development Command, Hanscom, AFB, MA 01731

4. L.E. Halliburton, N. Koumvakalis, M.E. Markes, J.J. Martin, J. Appl. Phys. 52, 3565 (1981)

5. L.E. Halliburton, Cryst. Lattice Defects Amorph. Mater. 12, 163 (1985)

6. L.E. Halliburton, M.E. Markes, J.J. Martin, in Proceedings of the 34th Annual Frequency Control Symposium (1980), pp. 1-8. Copies available from National Technical Information Service (NTIS), 5285 Port Royal Road, Sills Bldg., Springfield, VA 22161

7. J.J. Martin, B.H. Hwang, H. Bahadur, G.A. Berman, J. Appl. Phys. 65, 4666 (1989)

8. H. Bahadur, J. Appl. Phys. 66, 4973 (1989)

9. H. Bahadur, J. Appl. Phys. 73, 7790 (1993)

10. H. Bahadur, IEEE Trans. Ultrason. Ferroelectr. Freq. Control 41, 820 (1994)

11. H. Bahadur, J. Appl. Phys. 75, 1421 (1994)

12. H. Bahadur, IEEE Trans. Nucl. Sci. 39, 2170 (1992)

13. H. Bahadur, IEEE Trans. Ultrason. Ferroelectr. Freq. Control, 47, 1190 (2000)

14. R.H.D. Nuttall, J.A. Weil, Can. J. Phys. 59, 1696 (1981)

15. R.H.D. Nuttall, J.A. Weil, Can. J. Phys. 59, 1709 (1981)

16. S. Toyoda, in Production and Decay Characteristics of Paramagnetic Defects in Quartz: Applications to ESR Dating. Ph.D. Thesis, Osaka University, Toyonaka, Osaka, Japan, 1992

17. M. Ikeya, in New Applications of Electron Spin Resonance, Dating, Dosimetry and Microscopy (World Scientific, Singapore, New Jersey, London, Hong Kong, 1993)

18. M.C.M. O'Brien, M.H.L. Pryce, in Defects in Crystalline Solids (Bristol Conference, London, Phys. Soc. London, England, 1955), p. 88

19. M.C.M. O'Brien, Proc. R. Soc. Lond. A231, 404 (1955)

20. J.A. Weil, Phys. Chem. Minerals 10, 149 (1984) 